Meta

Journal des traducteurs

Translators' Journal

\title{
The General Bilingual Dictionary as a Working Tool in Thème
}

\section{Ingrid Meyer}

Volume 33, numéro 3, septembre 1988

URI : https://id.erudit.org/iderudit/003645ar

DOI : https://doi.org/10.7202/003645ar

Aller au sommaire du numéro

Éditeur(s)

Les Presses de l'Université de Montréal

ISSN

0026-0452 (imprimé)

1492-1421 (numérique)

Découvrir la revue

Citer cet article

Meyer, I. (1988). The General Bilingual Dictionary as a Working Tool in Thème. Meta, 33(3), 368-376. https://doi.org/10.7202/003645ar

\section{Résumé de l'article}

Because of his lack of native-speaker intuition for the target language, the thème translator requires of the general bilingual dictionary much more explicit lexical information than does his version counterpart. On the basis of a study of lexical errors made by thème translation students, we examine the weaknesses of the general bilingual dictionary for thème, and relate these to either a non-observance of lexicographic principles, or to a lack of such principles. Finally, we propose three teaching strategies to help thème translation students deal with the general bilingual dictionary.
Ce document est protégé par la loi sur le droit d'auteur. L'utilisation des services d'Érudit (y compris la reproduction) est assujettie à sa politique d'utilisation que vous pouvez consulter en ligne.

https://apropos.erudit.org/fr/usagers/politique-dutilisation/ 


\title{
THE GENERAL BILINGUAL DICTIONARY AS A WORKING TOOL IN THEME
}

INGRID MEYER

University of Ottawa, Ottawa, Ontario, Canada

\begin{abstract}
Because of his lack of native-speaker intuition for the target language, the thème translator requires of the general bilingual dictionary much more explicit lexical information than does his version counterpart. On the basis of a study of lexical errors made by thème translation students, we examine the weaknesses of the general bilingual dictionary for thème, and relate these to either a non-observance of lexicographic principles, or to a lack of such principles. Finally, we propose three teaching strategies to help thème translation students deal with the general bilingual dictionary.
\end{abstract}

\section{INTRODUCTION}

Almost every translator, it seems, possesses a collection of favorite lexical gaffs committed as a result of naive reliance on a general bilingual dictionary (GBD). Student translators are particularly prone to being led astray by the GBD, as evidenced by the frequent wail, "But I found it in the dictionary !", all too familair to their teachers. The beginning student's faith in the GBD generally changes to apprehension rather quickly, however, as he discovers - principally through trial and error - that this working tool cannot be trusted blindly. Apprehension about the GBD is especially strong for translation into the non-native language, or theme (as opposed to translation into the native language, or version $)^{1}$. The reason is the thème translator's lack of native-speaker intuition regarding the GBD's proposed target language (TL) equivalents - that intuition which allows his version counterpart 1) to make the semantic and stylistic judgements needed in accepting or rejecting a TL equivalent, or in choosing from among several equivalents proposed, and 2) to properly combine the TL item, once correctly selected, with other items in context. The GBD's mandate in thème is thus much more extensive than in version : as well as giving the TL equivalent(s) for a source language (SL) item, it must provide explicitly much of the information about the TL item(s) known intuitively to a native TL speaker. This mandate, judging from the frequent complaints voiced by translators, seems to be inconsistently fulfilled by the GBD - despite, of course, its many benefits (it is certainly one of the translator's most often used, and valuable, tools).

In this paper, we propose an analysis of typical GBD weaknesses with regard to translation into the non-native language. Our analysis is based on a study of lexical errors made by francophone students (School of Translators and Interpreters, University of Ottawa) when translating from French into English. Lexical errors were used as the starting point for the analysis as they indicate problem words for the translator, and are thus the words he will need help with most from his GBD. Over a two-year period, translated texts were collected from the three French-English thème courses offered at the School. For each course, seven texts per year were selected at random, yielding 42 different texts with an average length of 230 words. All texts were non-technical in the sense that they were intended for the general, educated public. For each lexical error 
found in the students' translations, the pertinent SL item was checked in two GBDs to see whether they had handled the item adequately. Errors pointing out no weakness in either GBD were discarded, the others retained and the dictionary problem noted.

The two GBDs consulted were those most often used by our translation students : le Robert \& Collins Dictionnaire français-anglais/anglais-français ( $\mathrm{RC})$, and Harrap's New Standard French and English Dictionary, vol. 1 and 2 (HA). We should like to emphasize that the following analysis is not intended as a critique of these GBDs specifically - on the contrary, we feel they represent an important contribution to bilingual lexicography, and furthermore, recommend them to our own students. The weaknesses pointed out are related to general principles applying, to the best of our knowledge, to all GBDs and are not specific to any one. It should furthermore be noted that our study in no way attempted to weigh the dictionary weaknesses found against the many benefits of the GBD in general - or either one of the GBDs consulted - as a working tool in thème (we assumed that, as the provider of lexical equivalents between languages, the GBD is an indispensable tool to any translator).

\section{ANALYSIS OF GBD WEAKNESSES}

The weaknesses pointed out by our study of lexical errors could eventually be classified into two principal types : weaknesses impeding the theme translator's selection of the appropriate TL item, and weaknesses impeding his combination of the TL item, once correctly selected, with other items in context. Further subdivisions emerged within these principal types, and are presented below, illustrated with examples of student errors. The following abbreviations will be used :

SLT excerpt from SL (French) text

ERR excerpt from TL (English) text containing student lexical error

?ERR excerpt from TL (English) text containing a lexical item which would not be marked an error in class, but for which a more appropriate variant exists

COR our proposed correction(s) of lexical error (to facilitate discussion, we have limited correction variants to two and avoided variants entailing extensive reorganization of the TL text)

\subsection{WEAKNESSES AFFECTING SELECTION}

Three basic types of GBD weaknesses were noted : absence of the SL lexical item ; absence of an appropriate TL item; inadequate discrimination between TL items proposed.

\section{(A) Absence of SL item}

SL items were found to be absent for two principal types of items : multi-lexemic items (i.e. compounds and idioms), and syntagms corresponding to a single lexical item in the TL. While both RC and HA list many such items, their listings are not exhaustive, as the following examples illustrate.

$$
\begin{array}{ll}
\text { SLT } & \ldots \text { la moyenne de vie dans les ghettos est passée de } \\
& 68 \text { à } 64 \text { ans en quelques années... } \\
\text { ERR } & \ldots \text { the average life... } \\
\text { COR } & \ldots \text { the average life expectancy... }
\end{array}
$$

While RC and HA provide lists of possible equivalents for both moyenne and vie, neither indicates how to translate this compound. Similar multi-lexemic items are, however, provided — for example, moyenne d'âge/des températures/des gens with their 
equivalents average age/temperature/person are found in RC. (One can easily see how the theme user might, based on these examples, make the faulty deduction that moyenne de vie could translate as average life.)

(2) SLT Ainsi, tout en déterminant avec le plus de réalisme possible les besoins futurs d'électricité des Québécois...

ERR ... while it must determine with as much realism as possible...

COR $\quad .$. while it must determine as realistically as possible...

While réalisme is listed in both $\mathrm{RC}$ and $\mathrm{HA}$, avec réalisme is not. Consequently, there is nothing to tell the thème user that with realism sounds odd in English, in contrast to similar French syntagms (avec enthousiasme, avec soin) which can be translated by a syntagm or lexical item (with enthusiasm/enthusiastically, with care/carefully).

\section{(B) Absence of TL item}

Absence of an appropriate TL item could be related to three types of phenomenon : differences in semantic extension, in stylistic extension, and in grammatical category.

(3) SLT D'autre part, les encouragements à l'économie d'énergie et une rationalisation plus poussée de la consommation d'électricité peuvent modifier la progression de la demande...

ERR ... energy-saving/energy conservation encouragement...

... encouragement for saving/conserving energy...

COR $\quad . .$. energy/saving/energy conservation incentives... ... incentives to save/conserve energy...

(4) SLT

Le sol québécois ne contient que de faibles quantités de gaz naturel.

ERR Quebec's soil contains only...

COR Quebec has only...

The student making the error in (3) was likely unaware that English has the term incentive, denoting a special kind of encouragement - specific rewards for achieving a goal. RC does not list incentive at all as a possible equivalent for encouragement (interestingly, though, it provides encouragement as an equivalent for incentive on its EnglishFrench side). HA provides incentive only in one of its examples : "e. à la vertu, incentive to virtue" - hardly a clear indication that incentive is the best choice in (3).

In example (4), the difference in semantic extension between sol and soil entails some restructuring in the TL text. While soil designates the sense of 'thin surface layer of the earth supporting plant life', sol has a much broader extension, designating 'a thin surface layer' (as in the context of farming) as well as 'a very deep layer' (as in the context of mining). Neither RC nor HA, providing only the common equivalents earth, soil, ground, etc., would be of any help to the theme user in this case.

... les peuples de l'hémisphère sud peuvent se nourrir eux-mêmes. Déjà, des initiatives sont prises là-bas pour y parvenir... Ces efforts, nous devons les soutenir. Hélas, ces efforts sont parfois découragés par certaines interventions des pays riches.

[From an advertisement, put out by Action aide alimentaire, aimed 
at getting support for this organization's efforts in third world countries.]

ERR $\quad$... Alas, these efforts..

COR ... Unfortunately/Sadly, these efforts...

Example (5) illustrates a case where the GBD failed to account for differences in stylistic extension between words : neither RC nor HA indicates explicitly that alas is virtually unusuable in modern English. Only RC might have put a dictionary-user on his guard against using alas, albeit indirectly : while it lists alas as the normal equivalent for hélas, it includes some examples where unfortunately is used : "mais, ils n'ont pas pu en profiter but unfortunately ou sadly they were not able to reap the benefits of it". It is important to note that the lack of stylistic indication for alas is not due to a general absence of stylistic labelling in the two GBDs consulted. On the contrary, both set the principle of indicating stylistic variation on four dimensions : register, temporal dialect, spatial dialect, and field. In this case, RC and $\mathrm{HA}$ could have provided, respectively, their temporal dialect indicators " $\downarrow$ " (old-fashioned usage) and "A" (archaic usage).

(6) SLT

L'industrie ne manqua pas de repérer l'importance de ces nouveaux marchés...

ERR Industry did not miss seeing...

COR Industry was quick to see/soon saw...

Example (6) illustrates a change of grammatical category in passing from SL to TL (a phenomenon known as transposition ${ }^{2}$ ). Neither RC nor HA indicates the verbadverb transposition necessary in this case (nor the negative-positive modulation entailed). It is interesting, however, that both GBDs do list ne pas manquer de, with equivalents involving transposition, but only in the sense of 'remembering to do something', and not of "quickly taking the opportunity to do something", as is the case here. This failure to indicate transposition is thus simply an omission, and not an absence of such indication in principle.

(C) Inadequate discrimination between proposed equivalents

This section deals with cases where an appropriate TL equivalent was listed in the GBD, but where the user would have difficulty selecting it because of inadequate discrimination between proposed equivalents. Two types of necessary discrimination were noted : semantic and stylistic.

Le candidat devra absolument avoir un diplôme universitaire, de préférence une maîtrise en gestion (MBA) avec concentration en... [from a job advertisement]

ERR Candidates must have...

COR Applicants must have...

While RC and HA both provide applicant and candidate as possible equivalents for candidat, neither indicates that unlike French, English differentiates between all persons applying for a position (applicants) and those who, among all the applicants, are considered seriously for the position after preliminary screening (candidates). This absence of indicating material is, however, not due to a lack of such material in the two GBDs overall. Both provide some meaning discrimination through partial definitions, field labels, synonyms, etc. The more subtle the differences in meaning between the TL items proposed, however, the more infrequent discrimination seems to be. 
SLT La vie de Mozart ne présente guère d'intérêt pour qui veut comprendre sa musique. Elle se réduit d'ailleurs à peu de chose...

ERR $\quad$... In effect, it boils down to...

COR $\quad$... In effect, it amounts to...

The thème translator looking up se réduire $a$ in $\mathrm{RC}$ will find no indication of a stylistic difference between boil down to and amount to, the two equivalents proposed. HA, on the other hand, does label boil down to as familiar usage. Though RC possesses a roughly equivalent label ("*") to cover this type of register, it simply does not use it. The problem is similar in other cases relating to stylistic discrimination : while both GBDs set the principle of providing such discrimination, they do not always follow this principle.

\subsection{WEAKNESSES AFFECTING COMBINATION}

GBD weaknesses impeding the user's proper combination of a TL item, once correctly selected, were noted in three areas : morphology, syntax, and restricted lexical cooccurrence.

\section{(A) Morphology}

The two principal types of morphological problems noted in the lexical errors of our students were the use of an improper form for irregular verbs or nouns, and the failure to recognize non-count nouns in English and use them properly. As regards the former, both HA and RC indicate morphological irregularities, but only for SL headwords - the wrong place for the thème translator, who needs such information for the TL equivalents, and is thus forced to use the GBD backwards or to consult a unilingual English dictionary for this information. As regards uncountability, only RC, of the two GBDs consulted, uses a symbol [U] to indicate this property. Even RC, however, does not indicate all cases of uncountability, as it states explicitly in its Introduction (p. xvi) : "The symbol [U] occurs only as a warning device in cases where a non-native speaker might otherwise use the word wrongly. There has been no attempt to give an exhaustive account of 'uncountability' in English". RC's criteria for deciding when a non-native speaker might "use the word wrongly" are not given. Our error analysis showed many cases of student error in this regard, as illustrated in the following example;

(9) SLT Ce nouveau projet exigera une planification constante...

ERR The/This new projet will require/call for $a$ constant planning...

COR The/This new project will require/call for constant planning...

Although planning is obviously a problem word for the theme translator making this error, RC does not indicate its uncountability, and thus the impossibility of using the indefinite article in English.

(B) Syntax

Because of his lack of native-speaker intuition, the theme translator may sometimes need indications on the way in which a lexical item combines with its syntactic actants (those lexical items syntactically dependent on it), i.e. the surface forms which these syntactic actants can take. While RC and HA provide some syntactic information, their criteria for its inclusion and exclusion are not completely clear : only RC attempts to explain its procedure, though vaguely, stating (p. xv) that it provides "Syntactical information to allow the non-native speaker to use the word correctly". Despite its good intentions, the GBD does not always meet the theme user's need for syntactic indications, as illustrated below. 
(10) SLT

ERR

COR

ERR

COR
... un plan n'est jamais terminé. Il doit être enrichi constamment de nouvelles données.

... it must constantly be enriched of...

... it must constantly be enriched with/by...

Deux ouvrages sur la famille ont été publiés ces derniers temps en France. Ils permettent de préciser certains aspects de l'évolution des structures familiales.

... They allow to specify...

... They allow one to specify...

Examples (10) and (11) illustrate, respectively, the need for a GBD to indicate both the syntactic possibilities and the syntactic restrictions for a lexical item. In (10), the thème user needs to know that the second syntactic actant of enriched requires the preposition with or by, an indication supplied in neither RC nor HA. In (11), he needs to know that unlike permettre, allow cannot be used without the addressee complement. While both RC and HA supply the propositional form permettre à quelqu'un de faire quelque chose, neither gives an example of permettre used without the addressee complement.

\section{(C) Restricted lexical co-occurrence}

By restricted lexical co-occurrence we mean phraseological combinations describable in terms of lexical functions. The lexical function is a lexicographic innovation postulated by A.K. Žolkovskij and I.A. Mel'cuk (Žolkovskij - Mel'čuk 1965) and is, roughly, a meaning whose lexical realization varies according to the lexical item with which it is syntagmatically associated in a text ${ }^{3}$. An example is the function Magn which conveys the general sense 'very', and which can be lexicalized in various ways : a raging storm, strictly prohibited, to bleed profusely, thin as a rake, etc.

While many dictionaries indicate restricted lexical co-occurrence to some degree, there is only one which indicates all instances of such occurrence systematically, by means of a limited number of standard lexical functions : the Explanatory Combinatorial Dictionary (ECD), initial volumes of which have been published for French and Russian (Mel'cuk et al. 1984a, 1984b). Unlike the ECD, GBDs do not present restricted lexical co-occurrence either systematically or exhaustively, as the following examples illustrate.

\section{(12) SLT}

... même soûl perdu, un Soviétique en service commandé ne prend pas d'initiative sans...

?ERR $\quad .$. even if he were very/extremely drunk...

COR ... even if he were dead/blind drunk...

Perdu is describable here as an exponent of the lexical function Magn for soûl. While RC and HA will quickly supply the dictionary user with an equivalent for soûl, only HA will provide one possible equivalent (blind) for perdu, under the entry for soûl.

(13) SLT On a refait le plafond, posé du papier peint...

$$
\begin{array}{ll}
\text { ERR } & \text {... fixed/put } \text { wall-paper... } \\
\text { COR } & \text {.. put up/hung wall-paper... }
\end{array}
$$

Poser is describable here as an exponent of the lexical function Real, corresponding to the general sense of 'doing with something what it is intended for'. While both RC 
and HA readily provide the proper equivalent for papier peint, the thème user would find no clear indication in either about what one typically "does" in English with wallpaper. He would find nothing under papier peint (where poser would be listed in an ECD, since papier peint is the headword of this phraseological combination). If he then looked under poser, he would find this term associated with many others, such as tableau, vitre, tapis, chauffage, etc., but not with papier peint.

The basic inconveniences of the GBD's unsystematic presentation of restricted lexical co-occurrence are three-fold : 1) Even when the co-occurrent is listed somewhere in the GBD, one can never be sure where it will be found - whether under the headword of the phraseological combination (i.e. soûl and papier peint), under the exponent of the lexical function (perdu, poser), or even under both ; 2) Finding the proper TL item within a dictionary entry can be time-consuming, as phraseological combinations are not given a separate section in the entry, and are generally found among idioms and miscellaneous examples of lexical items used in context ; 3) If the co-occurrent is not listed, the user must abandon the GBD - often after looking through long lists of expressions in various entries - for another tool.

\section{DISCUSSION}

The GBD weaknesses for thème pointed out by our analysis of student lexical errors can ultimately be related to one of two basic factors : a non-observance of lexicographic principles set forth on the one hand, and a simple lack of such principles on the other. Complicating a rigorous analysis of this dichotomy is the problem that many lexicographic principles, and particularly the specific conventions for their realization, must be deduced by studying dictionary entries, as they are not always explicitly formalized in the GBD's introductory remarks.

A non-observance of lexicographic principles in the GBD may be reflected in an error or in an omission (by which we designate conscious omissions, as opposed to unconscious ones, which we classify as errors). The presence of errors in a GBD, given the enormous volume of lexical material covered coupled with constant linguistic change, is of course simply a function of the human factor involved in dictionary compilation. Omissions, on the other hand, are typically explainable in terms of one general principle upon which all GBDs are compiled ${ }^{5}$, namely that, for commercial reasons, they are subject to material constraints and therefore cannot be exhaustive. As RC states quite explicitly (p. ix), "The desire to avoid an unduly lengthy and unwieldy volume has involved a certain choice". A non-observance of principles was seen in many of the examples presented in our analysis : while in principle the GBDs consulted account for differences in semantic and stylistic extension (evidenced by the numerous translation variants often supplied for an SL item), there are cases where certain possible variants are not given; while in principle they provide meaning discrimination for the variants proposed (as evidenced by the many types of indicating material at their disposal), there are cases where only a sign of punctuation indicates a meaning difference - and so on. Despite the lexicographic principles set forth, omissions may be made throughout the GBD in the interest of compromise - to make space for items considered more vital.

Some GBD weaknesses, on the other hand, are related to a lack of formalized principles for dealing with a particular lexicographic phenomenon. The most notable example indicated in our study was that of restricted lexical co-occurrence. Since the GBD has no formalized mechanism (i.e. lexical functions) for dealing with phraseological combinations (i.e. separating them from idioms, classifying them), the dictionary user can never be sure that a particular combination will be listed, or precisely where he should look for it. In other cases, it is a lack of formalization of the specific conventions 
for realizing a lexicographic principle which causes problems in the GBD. One area where formalization of conventions seems particularly unclear is the separation of lexical information provided explicitly from that provided in examples of the SL item used in context. As illustrated in (5), translation variants may sometimes be given in the GBD's initial listing of possible TL equivalents, other times in an example. (In many cases, they are given in both.) A similar tendency was noted for syntactic information. The apparent lack of formalized lexicographic conventions in this regard is clearly a drawback for the dictionary user, who can never be quite sure in which part of the GBD entry the needed information will be found. Furthermore, if this information is given only in an example which stands alone (as opposed to an example illustrating information given explicitly), he may still not be sure - as in (5) - that the example is applicable to his context.

Despite great advances over the century, the GBD still has a long way to go before it completely satisfies the thème translator. Errors need to be corrected, omissions eliminated (the latter will require rethinking - possibly encouraged by advancing computer technology - of the assumption that dictionaries cannot be exhaustive). New lexicographic principles will have to be established, while many of those already put forth will require more explicit formalization. Clearly, thème translators need their own GBDs in many, if not most, cases (i.e. HA and RC), the GBD tries to accommodate both thème and version users, despite their very different needs.

But while they wait for changes in the GBD, thème translators need to live with this important working tool as painlessly as possible. This implies, for the translation classroom, tackling the following questions : 1) Why does the conventional GBD present weaknesses in thème? 2) What are these weaknesses? 3) How can the thème user best deal with them ? Specifically, the theme translation student needs some theoretical background to the principles of bilingual lexicography, coupled with an analysis of his specific requirements as a thème user. Second, he needs a systematic overview of the GBD's potential pitfalls for thème, ideally illustrated with pertinent, structured dictionary consultation. Last, he needs an understanding of how to complement the GBD when necessary - for example, with a unilingual TL dictionary (preferably one designed for advanced language learners ${ }^{6}$ ), documentation on the subject matter, consultation with native TL speakers, etc. By tackling these three issues as part of their translator training, our students may at least gain some "focus" for their apprehensions about the GBD - even though such apprehensions will likely not disappear until this working tool is significantly improved.

\section{ACKNOWLEDGMENTS}

The draft of the present article, as well as the more detailed chapter of my Ph.D. thesis which it summaries, were carefully read by Igor A. Mel'čuk and Roda P. Roberts. I am most grateful for their many lucid criticisms and suggestions.

Notes

1. The skills acquired through translation into a non-native language are in some ways applicable to translation into a native sublanguage (i.e. the "language" of a specialized field of knowledge) when the translator is not very familiar with the sublanguage. While a detailed examination of the similarities between these two translation types is beyond the scope of this paper, it is interesting to note that both force the translator to rely on dictionaries for much of the lexical information (meaning discrimination, lexical co-occurrence, etc.) which his native speaker intuition supplies when he translates non-specialized texts into his mother tongue.

2. For a classic study of this phenomenon in English and French, cf. Vinay and Darbelnet (1958 : 96-101). Our investigation was limited to terms for which transposition is obligatory (what Vinay and Darbelnet term transposition obligatoire, as opposed to transposition facultative). 
3. For a detailed explanation of the lexical function, cf. Mel'cuk (1982: 27-44).

4. Some of the better examples are the Oxford Advanced Learner's Dictionary by A.S. Hornby, Kenkyusha's New Dictionary of English Collocations, Ed. S. Katsumata, and Petit dictionnaire de style à l'usage des Allemands as well as $\boldsymbol{A}$ Dictionary of English Style, both by A. Reum.

5. As well as all unilingual dictionaries, except the ECD.

6. For English, good examples are The Oxford Advanced Learner's Dictionary of Current English by A.S. Hornby and The Longman Dictionary of Contemporary English.

\section{REFERENCES}

Collins-Robert French-English/English-French Dictionary, 1979, London, Collins.

Harrap's New Standard French and English Dictionary (vol. 1 and 2, French-English), 1977, London, Harrap.

HORNBY, A.S. (1974) : Oxford Advanced Learner's Dictionary of Current English (3rd ed.), Oxford University Press.

KATSUMATA, S. (ed.) (1957) : Kenkyusha's New Dictionary of English Collocations, Tokyo, Kenkyusha. Longman Dictionary of Contemporary English, 1978, Harlow (England), Longman.

MEL'CUK, I.A. (1982) : "Lexical Functions in Lexicographic Description", in Proceedings of the VIIIth Annual Meeting of the Berkeley Linguistic Society, Berkeley, UCB, pp. 427-444.

MEL'ČUK, I.A. et al. (1984a) : Dictionnaire explicatif et combinatoire du français contemporain. Recherches lexico-sémantiques 1, Montréal, Les Presses de l'Université de Montréal.

MEL'ČUK, I.A. et al. (1984b) : Explanatory Combinatorial Dictionary of Modern Russian : SemanticoSyntactic Studies of Russian Vocabulary, Vienna, Wiener Slawistischer Almanach.

VINAY, J.-P. and J. DARBELNET (1958) : Stylistique comparée du français et de l'anglais, Paris, Didier.

ŽOLKOVSKIJ, A.K. and I.A. MEL'ĆUK (1965) : "O vozmožnom metode $i$ instrumentax semanticeskogo sinteza", in Naučno-textničeskaja informacija, $\mathrm{n}^{\circ}$ 5, pp. 23-28. 